\title{
PERENCANAAN STRATEGIS SISTEM \\ INFORMASI MENGGUNAKAN METODE WARD AND PEPPARD (Studi Kasus: Universitas Sangga Buana YPKP Bandung)
}

\author{
Asep Muhammad Indra Purnama ${ }^{1}$, Gitasha Noviana ${ }^{2}$, \\ ${ }^{1,2}$ Program Studi Sistem Informasi, Fakultas Teknik, Universitas Sangga Buana, Bandung \\ 1indra.purnama1985@gmail.com, ${ }^{2}$ gith291197@gmail.com
}

\begin{abstract}
ABSTRAK
Sangga Buana YPKP Bandung merupakan salah satu lembaga Pendidikan/Perguruan Tinggi Swasta yang ada di Bandung. Dimana dalam persaingan dengan Perguruan Tinggi lain memerlukan suatu rencana strategis untuk membedakan dan memberi keunggulan dalam bersaing. Sangga Buana YPKP Bandung telah menyediakan sistem informasi dan teknologi informasi yang sudah mencukupi untuk mendukung kegiatan bisnis sebagai upaya meningkatan kualitas dan daya saing perguruan tinggi, namun kondisi sistem informasi yang ada masih dirasa belum efisien dikarenakan masih ada beberapa sistem yang belum saling terintegrasi dengan baik antar unit kerja, masih ada aktifitas yang dilakukan secara manual, dan belum adanya perencanaan yang dilakukan dalam pengembangan sistem informasi sebelumnya. Maka dari itu dilakukan penelitian ini merupakan upaya untuk membangun suatu perencanaan strategis sistem informasi menggunakan metode Ward and Peppard. Tools yang digunakan yaitu SWOT dan Value Chain untuk menganalis lingkungan bisnis internal dan PEST dan Porter's Five Force untuk menganalisis lingkungan bisnis eksternal, Mc Farlan's Strategic Grid untuk memetakan portofolio aplikasi. Dimana hasil dari Penelitian ini berupa kerangka kerja strategis dan rekomendasi aplikasi yang dibutuhkan oleh Universitas Sangga Buana YPKP Bandung.
\end{abstract}

Kata Kunci: Perencanaan Strategis SI/TI; Perguruan Tinggi; Ward and Peppard; MC Farlan Strategic Grid

\section{PENDAHULUAN}

Sistem informasi dan teknologi informasi pada saat ini sangat berperan penting dalam setiap kegiatan di suatu organisasi, dimana dalam pencapaian tujuan organisasi tidak lepas dari suatu sistem informasi yang akan berguna untuk mempermudah suatu pekerjaan atau tugas yang akan dikerjakan, dan meningkatkan keakuratan informasi dan dalam proses pengambilan keputusan. Sistem informasi penerapannya perlu dilakukan manajemen strategi agar sistem informasi terkelola dan sesuai dengan yang dibutuhkan organisasi sehingga selaras dengan rencana strategis bisnis dalam proses pencapaian tujuan.

Perencanaan strategis merupakan salah satu langkah manajemen strategi yang perlu dilakukan suatu organisasi sebelum pengimplementasian suatu sistem informasi yang akan diterapkan, dengan perencanaan yang strategis dengan menguraikan semua faktor-faktor yang dapat mempengaruhi tercapaianya visi, misi, dan tujuan organisasi.
Menurut ward dan Griffiths, 1996 Perencanaan Strategis sistem informasi adalah pendekatan Sistematis dalam menentukan manayang paling efektif dan efisien berkaitan dengan kepuasan pemenuhan kebutuhan informasi. Pengembangan sistem informasi yang tidak terencana secara sistematis akan mengakibatkan organisasi tidak memiliki skala prioritas proyek pengembangan SI/TI dan terkesan tambal sulam. Cara seperti ini akan berdampak pada penurunan produktivitas organisasi [1].

Perguruan Tinggi merupakan salah satu organisasi resmi yang merupakan suatu lembaga pendidikan tempat berlangsungnya proses penyebaran ilmu pengetahuan atau proses pembelajaran dimana didalamnya terdapat beberapa elemen pendukung yang saling berhubungan satu sama lain yang akan melakukan kegiatan sesuai dengan tugas masing- masing. Universitas merupakan salah satu contoh instansi yang didalamnya memerlukan penerapan sistem informasi yang 
akan mempermudah pelayanan dan pelaksanaan tugas yang ada dan sangat penting untuk pencapaian tujuan di Universitas.

Dalam suatu Perguruan tinggi atau lembaga pendidikan tinggi dapat mengurangi risiko terkait dalam pengambilan keputusan sistem informasi apabila memiliki rencana strategis yang baik.[2]

\section{TEORI PENDUKUNG}

\subsection{Sistem Informasi}

Menurut Laudon (2014), sistem informasi didefinisikan sebagai seperangkat komponen yang saling terkait yang mengumpulkan, memproses, menyimpan, dan mendistribusikan informasi untuk mendukung pengambilan keputusan dan pengendalian dalam sebuah organisasi. Selain mendukung pengambilan keputusan, koordinasi, dan pengendalian, sistem informasi juga dapat membantu manajer dan pekerja menganalisis masalah, memvisualisasikan subyek yang kompleks, dan menciptakan produk baru.[3]

\subsection{Perencanaan Strategis Sistem Informasi}

Rencana strategis (renstra) merupakan proses dan upaya-upaya perencanaan terpadu dan komprehensif yang berorientasi pada hasil yang ingin dicapai selama kurun waktu tertentu dengan memperhitungkan potensi dan kelemahan yang dimiliki serta peluang dan kendala yang mungkin timbul. Perencanaan strategis SI adalah untuk menentukan sistem informasi yang dibutuhkan dalam mendukung strategi bisnis, sehingga strategi berkonsentrasi untuk mengidentifikasi informasi yang dibutuhkan dan memastikan bahwa sistem informasi selaras dengan strategi bisnis. Perencanaan strategis sistem informasi sebagai proses untuk menghasilkan program implementasi dan penggunaan sistem informasi untuk mengoptimalkan efektivitas sumber daya informasi dan menggunakannya semaksimal mungkin dalam rangka mencapai tujuan organisasi.[4]

Perencanaan strategis adalah suatu proses dengan mengidentifikasi, mengevaluasi dan memutuskan strategi yang harus dilakukan oleh organisasi. Sedangkan perencanaan strategis SI/TI merupakan proses identifikasi aplikasi SI berbasis komputer yang akan mendukung dalam pelaksanaan rencana bisnis. Perencanaan strategis SI/TI mempelajari pengaruh SI/TI terhadap kinerja bisnis dan kontribusi bagi organisasi dalam menjalankan bisnisnya. Selain itu, perencanaan strategis SI/TI juga menjelaskan berbagai tools, teknik, dan kerangka kerja bagi manajemen untuk menyelaraskan strategis SI/TI dengan strategis bisnis, bahkan mencari kesempatan baru melalui penerapan teknologi yang inovatif. (Ward \& Peppard, 2002).[5]

Remenyi dalam Rogerson \& Fidler. mendefinisikan Perencanaan Strategis Sistem Informasi sebagai proses untuk menghasilkan program implementasi dan penggunaan sistem informasi untuk mengoptimalkan efektivitas sumber daya informasi dan menggunakannya semaksimal mungkin dalam rangka mencapai tujuan organisasi [6]

Perencanaan strategis SI/TI merupakan proses identifikasi portofolio aplikasi SI berbasis komputer yang akan mendukung organisasi dalam pelaksanaan rencana bisnis dan merealisasikan tujuan bisnisnya. Perencanaan strategis SI/TI mempelajari pengaruh SI/TI terhadap. inerja bisnis dan kontribusi bagi organisasi dalam memilih langkah-langkah strategis. Selain itu, perencanaan strategis SI/TI juga menjelaskan berbagai alat, teknik, dan kerangka kerja bagi manajemen untuk menyelaraskan strategi SI/TI dengan strategi bisnis, bahkan mencari kesempatan baru melalui penerapan teknologi yang inovatif (Ward dan Peppard, 2002).[7]

\subsection{Strategi SI dan Srategi TI}

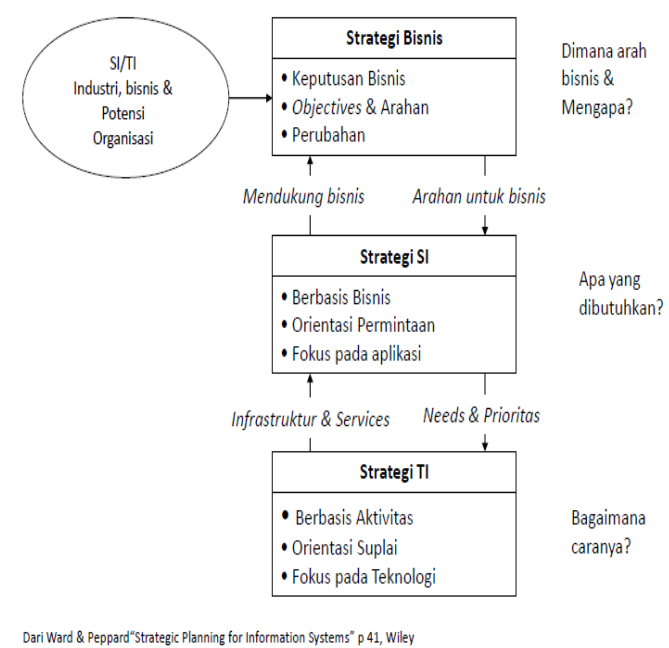

Gambar 2.1 Hubungan strategi SI/TI dengan Strategi Bisnis.[1] 
Earl membedakan antara strategi SI dan TI. Strategi SI lebih menekankan pada penentuan aplikasi sistem informasi yang dibutuhkan oleh organisasi. Sedangkan strategi TI lebih menekankan pada pemilihan teknologi, infrastruktur dan keahlian khusus yang terkait.

\subsection{Proses perencanaan SI/TI berdasarkan Ward and Peppard}

Menurut Ward and Peppard (2002), perencanaan strategis SI/TI harus berdasarkan pada lingkungan bisnis internal dan eksternal serta lingkungan SI/TI internal dan eksternal. Kemudian data tersebut akan dianalisis pada proses strategi SI/TI sehingga menghasilkan beberapa strategis bisnis SI, strategi manajemen SI/TI dan strategi TI. Dari ketiga hasil proses strategi SI/TI tersebut, kemudian dianalisis dan menghasilkan sebuah portofolio aplikasi untuk masa mendatang. Portofolio tersebut yang nantinya akan dijadikan dasar untuk melakukan pengembangan sistem informasi pada organisasi di masa akan datang. [8]

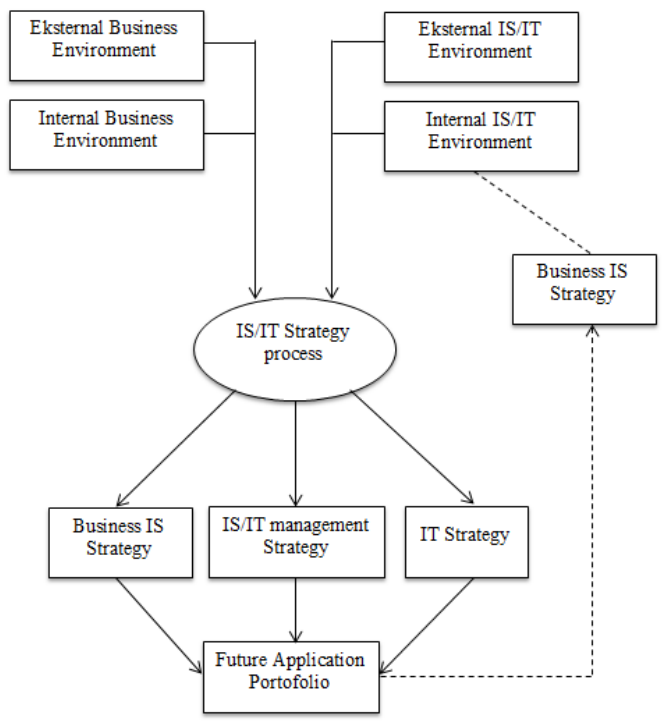

Gambar 2.2 Proses Perencanaan Metode Ward and Peppard

\section{METODOLOGI PENELITIAN}

\subsection{Kerangka Penelitian}

Berdasarkan Gambar 3.1 merupakan langkah-langkah yang dilakukan di dalam penelitian ini yaitu :

1. Dimulai dari proses Identifikasi masalah yang terjadi
2. Proses pengumpulan data berupa wawancara, observasi, Kuesioner dan studi literature.

3. Setelah pengumpulan data, dilakukan analisis menggunakan metode Ward and Peppard.

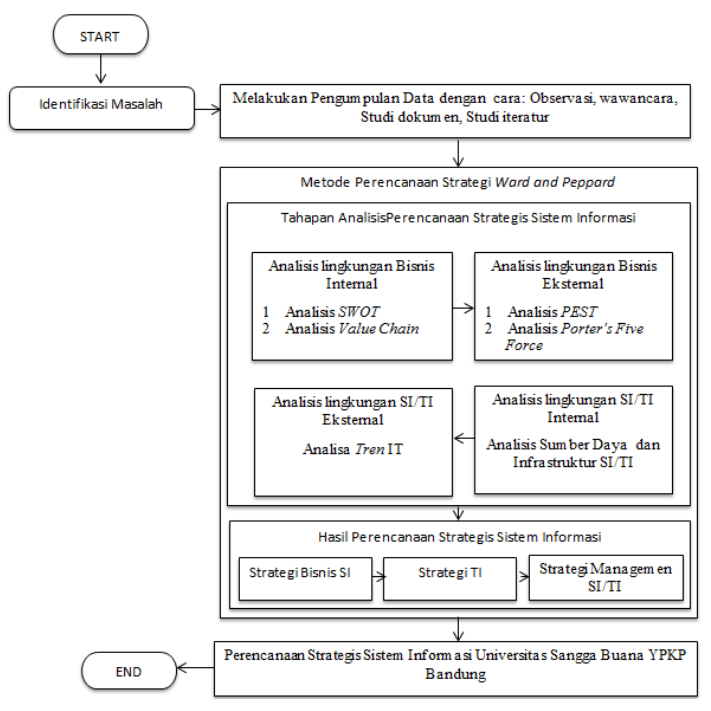

Gambar 3.1 Kerangka Penelitian

\subsection{Teknik Pengumpulan Data}

Pengumpulan data untuk penelitian ini dilakukan dengan beberapa teknik pengumpulan data yaitu antara lain:

\section{A. Wawancara}

Wawancara dilakukan terhadap pihak yang terkait di Universitas Sangga Buana YPKP Bandung. Wawancara dilakukan kepada tujuh narasumber yaitu:

a. Satu narasumber Bagian Akademik

b. Satu narasumber Bagian Kemahasiswaan dan Alumni

c. Dua narasumber Bagian Perpustakaan

d. Dua narasumber Bagian Direktoriat IT

e. Satu narasumber Bagian Sekretariat

Dari hasil wawancara tersebut, dikumpulkannya data dan informasi berupa kekuatan dan peluang yang dimiliki Universitas Sangga Buana YPKP Bandung., kelemahan dan ancaman yang dihadapi Universitas Sangga Buana YPKP Bandung, aktivitas yang dilakukan Universitas Sangga Buana YPKP Bandung.

\section{B. Observasi}

Observasi dilakukan pada bulan Maret 2020 yaitu di universitas Sangga Buana yang berlokasi di Jalan PH.H. Mustofa (Suci) No.68, Cikutra, Kec. Cibeunying Kidul, Kota 
Bandung, Jawa Barat 40124. Dari hasil observasi yang dilakukan, data dan informasi yang didapatkan yaitu sejarah singkat di universitas Sangga Buana Bandung, proses bisnis yang terdapat dalam perguruan tinggi, kondisi bisnis internal dan eksternal serta kondisi SI/TI internal dan eksternal.

\section{Studi Dokumen Institusi}

Dokumen yang dijadikan acuan dalam penelitian ini adalah dokumen mengenai rencana strategis Universitas Sangga Buana YPKP Bandung, dan informasi organisasi (visi, misi, tujuan dan struktur organisasi Universitas).

\section{Kuesioner}

Kuesioner dilakukan untuk mengetahui posisi sistem informasi di Universitas. Kuesioner disebarkan kepada 8 responden karyawan universitas Sangga Buana yang berhubungan langsung dengan aplikasi yang akan dinilai.

\section{E. Studi Literatur}

Studi literatur yang dilakukan pada penelitian ini meliputi internet, buku, jurnal serta paper yang terkait dengan penelitian.

\subsection{Metode Analisis Perencanaan Strategis Sistem Informasi}

Dalam enelitian ini metode yang digunakan adalah Ward and Peppard. Dalam metodologi ini terdiri dari beberapa alat/Tools yaitu sebagai berikut :

a. Analisis SWOT

Analisis ini dilakukan untuk menganalisis faktor-faktor strategis perusahaan yang terdiri dari kekuatan (Strengths), kelemahan (Weakness), peluang (Opportunities) dan ancaman (Threats) dalam kondisi yang ada saat ini pada Universitas Sangga Buana YPKP Bandung.

b. Analisis Value Chain

Analisis yang dilakukan untuk memetakan aktivitas-aktivitas yang terlibat di Universitas baik aktivitas utama dan pendukung.

c. Analisis PEST

Analisis faktor-faktor yang dapat mempengaruhi perguruan tinggi baik lingkungan politik, ekonomi, sosial maupun teknologi. d. Porter's Five Force (Analisis Lima Persaingan Porter)

Analisis ini dilakukan untuk menganalisis posisi Universitas Sangga Buana YPKP Bandung dalam industri dan mengetahui kekuatan eksternal yang dapat mempengaruhi jalannya proses bisnis.

\subsubsection{Hasil Analisis}

Berdasarkan hasil analisis menggunakan tools SWOT, Value Chain, PEST, dan Porter's Five Force maka akan menghasilkan :

1. Strategi Bisnis SI (Business IS Strategy)

Dalam tahapan ini keluaran yang dihasilkan berupa solusi strategi SI dan identifikasi solusi SI yang dibutuhkan oleh Universitas Sangga Buana YKP Bandung di masa yang akan mendatang

2. Strategi TI (IT Strategy)

Dalam tahapan ini keluaran yang dihasilkan berupa arahan pengembangan teknologi dan infrastruktur jaringan komputer organisasi yang dapat mendukung hasil rekomendasi strategi bisnis SI.

3. Strategi Manajemen SI/TI (IS/IT Management Strategy)

Dalam tahapan ini keluaran yang dihasilkan berupa usulan kebijakankebijakan dalam menerapkan strategi SI/TI.

\section{HASIL DAN PEMBAHASAN}

\subsection{Analisis}

\subsubsection{Analisis Lingkungan Bisnis Internal}

Analisis yang digunakan untuk menganalisis lingkungan bisnis internal Universitas Sangga Buana YPKP Bandung sebagai institusi perguruan tinggi yang menawarkan jasa dimana alat yang digunakan yaitu : Analisis SWOT, dan Analisis Value Chain.

\section{A. Analisis SWOT}

1. Strength/Kekuatan

Tabel 4.1 Analisis Strength/Kekuatan

\begin{tabular}{|l|l|}
\hline \multicolumn{2}{|c|}{ Strength/Kekuatan } \\
\hline S1 & Memiliki visi, misi dan tujuan yang jelas \\
\hline S2 & $\begin{array}{l}\text { Program studi yang ditawarkan cukup } \\
\text { banyak }\end{array}$ \\
\hline S3 & $\begin{array}{l}\text { Lokasi Universitas Sangga Buana YPKP } \\
\text { Bandung yang strategis (terletak di pusat }\end{array}$ \\
\hline
\end{tabular}




\begin{tabular}{|c|lr|}
\hline & $\begin{array}{l}\text { kota, mudah dijangkau berbagai sarana } \\
\text { transportasi) }\end{array}$ \\
\hline S4 & $\begin{array}{l}\text { Sistem pembayaran semester dapat } \\
\text { diangsur setiap bulan untuk memberikan } \\
\text { keringanan terhadap mahasiswa. }\end{array}$ \\
\hline S5 & $\begin{array}{l}\text { Memiliki pelayanan Sistem Informasi } \\
\text { yang fleksibel yaitu menerapkan sistem } \\
\text { pembelajaran online yang mudah diakses } \\
\text { dimanapun dan kapanpun. }\end{array}$ \\
\hline S6 & $\begin{array}{l}\text { Memiliki Tenaga pendidik dan } \\
\text { kependidikan sesuai standar nasional } \\
\text { Pendidikan Tinggi }\end{array}$ \\
\hline S7 & $\begin{array}{l}\text { Memiliki komitmen untuk maju } \\
\text { (peningkatan akreditasi prodi dan }\end{array}$ \\
\hline Sniversitas) & Banyak prodi terakreditasi B \\
\hline
\end{tabular}

\section{Weakness/Kelemahan}

Tabel 4.2 Analisis Strength/Kekuatan

\begin{tabular}{|c|c|}
\hline \multicolumn{2}{|r|}{ Weakness /Kelemahan } \\
\hline W1 & $\begin{array}{l}\text { Serapan mahasiswa baru yang rendah } \\
\text { untuk beberapa program studi }\end{array}$ \\
\hline $\mathrm{W} 2$ & $\begin{array}{l}\text { Sarana dan prasarana laboratorium } \\
\text { yang belum memadai }\end{array}$ \\
\hline W3 & $\begin{array}{l}\text { Hasil penelitian yang belum } \\
\text { berorientasi bisnis }\end{array}$ \\
\hline W4 & $\begin{array}{l}\text { Rata-rata masa tunggu kerja alumni } \\
\text { yang belum diketahui }\end{array}$ \\
\hline W5 & $\begin{array}{l}\text { Kinerja universitas di kancah nasional } \\
\text { dan internasional belum } \\
\text { teridentifikasi }\end{array}$ \\
\hline W6 & $\begin{array}{l}\text { Dosen berpendidikan doktor (S3) } \\
\text { masih sedikit dibanding jumlah dosen } \\
\text { berpendidikan Magister (S2) }\end{array}$ \\
\hline W7 & $\begin{array}{lrr}\text { Rendahnya } & \text { minat } & \text { dosen } \\
\text { berpendidikan } & \text { magister } & \text { (S2) } \\
\text { berjabatan akademik Lektor } & \text { Kepala } \\
\text { untuk melanjutkan ke jenjang doktoral }\end{array}$ \\
\hline W8 & $\begin{array}{l}\text { Pengelolaan aset, keuangan, } \\
\text { penatausahaan yang belum tercatat } \\
\text { dengan baik. }\end{array}$ \\
\hline W9 & $\begin{array}{l}\text { Kegiatan yang dilakukan masih ada } \\
\text { beberapa yang dilakukan secara } \\
\text { manual belum seluruhnya } \\
\text { terotomatisasi sehingga menghambat } \\
\text { prose bisni kampus }\end{array}$ \\
\hline W10 & $\begin{array}{lrr}\text { Penggunaan Teknologi Informasi } \\
\text { rendah, aktivitas belajar } & \text { mengajar } \\
\text { tidak menggunakan media yang baik, } \\
\text { fasilitas multimedia } & \text { tidak } \\
\text { dimanfaatkan semestinya } & \\
\end{array}$ \\
\hline W11 & $\begin{array}{l}\text { Manajemen di Universitas Sangga } \\
\text { Buana YPKP Bandung kurang dari } \\
\text { segi sarana \& prasarana }\end{array}$ \\
\hline W12 & $\begin{array}{l}\text { Sistem administrasi, terutama berkait } \\
\text { dengan data dan informasi belum } \\
\text { terintegrasi. Arus informasi sering } \\
\text { terputus, misalnya tentang rencana }\end{array}$ \\
\hline
\end{tabular}

kegiatan dan penganggaran yang tidak fleksibel.

\section{Opportunity/Peluang}

Tabel 4.3 Analisis Strength/Kekuatan

\begin{tabular}{|c|c|}
\hline \multicolumn{2}{|r|}{ Opportunity/Peluang } \\
\hline O1 & $\begin{array}{l}\text { Pengembangan kampus karena Lokasi } \\
\text { Strategis dan dapat dijangkau oleh } \\
\text { transportasi umum. }\end{array}$ \\
\hline $\mathrm{O} 2$ & $\begin{array}{l}\text { Peluang kerjasama dengan berbagai } \\
\text { pihak baik nasional maupun internasional } \\
\text { masih terbuka }\end{array}$ \\
\hline $\mathrm{O} 3$ & $\begin{array}{l}\text { Kerjasama Peningkatan kualitas tridarma } \\
\text { dengan lembaga lain masih terbuka }\end{array}$ \\
\hline $\mathrm{O} 4$ & $\begin{array}{l}\text { Minat masyarakat terhadap USB YPKP } \\
\text { masih relatif tinggi }\end{array}$ \\
\hline O5 & $\begin{array}{l}\text { Mekanisme E-learning/Pembelajaran } \\
\text { Jarak Jauh masih dikembangkan } \\
\text { Kemenristekdikti }\end{array}$ \\
\hline O6 & $\begin{array}{l}\text { Menyediakan layanan pemberian } \\
\text { beasiswa bagi } \begin{array}{r}\text { mahasiswa yang } \\
\text { berprestasi }\end{array} \\
\end{array}$ \\
\hline $\mathrm{O} 7$ & $\begin{array}{l}\text { Sistem informasi yang fleksibel dan } \\
\text { masih dikembangkan dengan berbagai } \\
\text { fitur pendukung lain }\end{array}$ \\
\hline O8 & $\begin{array}{l}\text { Adanya jalinan kerjasama dengan } \\
\text { lembaga memberi peluang terhadap } \\
\text { pengembangan dan pemberdayaan } \\
\text { kelembagaan }\end{array}$ \\
\hline O9 & $\begin{array}{l}\text { Tumbuh kembangnya kelompok } \\
\text { masyarakat profesional yang ingin } \\
\text { meningkatkan mutu akademik }\end{array}$ \\
\hline
\end{tabular}

4. Treath/Ancaman

Tabel 4.4 Analisis Strength/Kekuatan

\begin{tabular}{|c|l|}
\hline \multicolumn{3}{|c|}{ Treath/Ancaman } \\
\hline T1 & Kebijakan pemerintah yang berubah \\
\hline T2 & $\begin{array}{l}\text { Kebijakan pendidikan nasional yang } \\
\text { sering berubah (status kelola PT, } \\
\text { sinkronisasi kurikulum, pembatasan } \\
\text { jumlah fakultas dan program studi, dll) }\end{array}$ \\
\hline T3 & $\begin{array}{l}\text { Semakin banyak perguruan tinggi negeri } \\
\text { dan swasta di Indonesia yang tumbuh } \\
\text { profesional, sehingga menjadi kompetitor } \\
\text { bagi Universitas Sangga Buana untuk } \\
\text { bersaing mendapatkan input yang } \\
\text { berkualitas tingginya minat calon }\end{array}$ \\
\hline T4 & $\begin{array}{l}\text { Semakin d ta } \\
\text { mahasiswa Indonesia untuk belajar di } \\
\text { luar negeri }\end{array}$ \\
\hline T5 & $\begin{array}{l}\text { Trend masyarakat yang serba pragmatis } \\
\text { sehingga menginginkan lembaga } \\
\text { pendidikan yang memberikan jaminan } \\
\text { pekerjaan setelah lulus }\end{array}$ \\
\hline T6 & $\begin{array}{l}\text { Persaingan kerja lulusan yang samakin } \\
\text { ketat terutama pada era global, bukan }\end{array}$ \\
\hline
\end{tabular}




\begin{tabular}{|l|l|}
\hline & $\begin{array}{l}\text { hanya dengan lulusan dalam negeri tetapi } \\
\text { juga dengan tenaga kerja asing }\end{array}$ \\
\hline T7 & $\begin{array}{l}\text { Dinamika perubahan di dunia pendidikan } \\
\text { tinggi yang menuntut kreatifitas, inovasi, } \\
\text { dan tanggungjawab }\end{array}$ \\
\hline T8 & $\begin{array}{l}\text { Era globalisasi menuntut lulusan untuk } \\
\text { dapat bersaing dengan lulusan PT lain }\end{array}$ \\
\hline
\end{tabular}

Tabel 4.5 Matriks Hasil Analisis SWOT

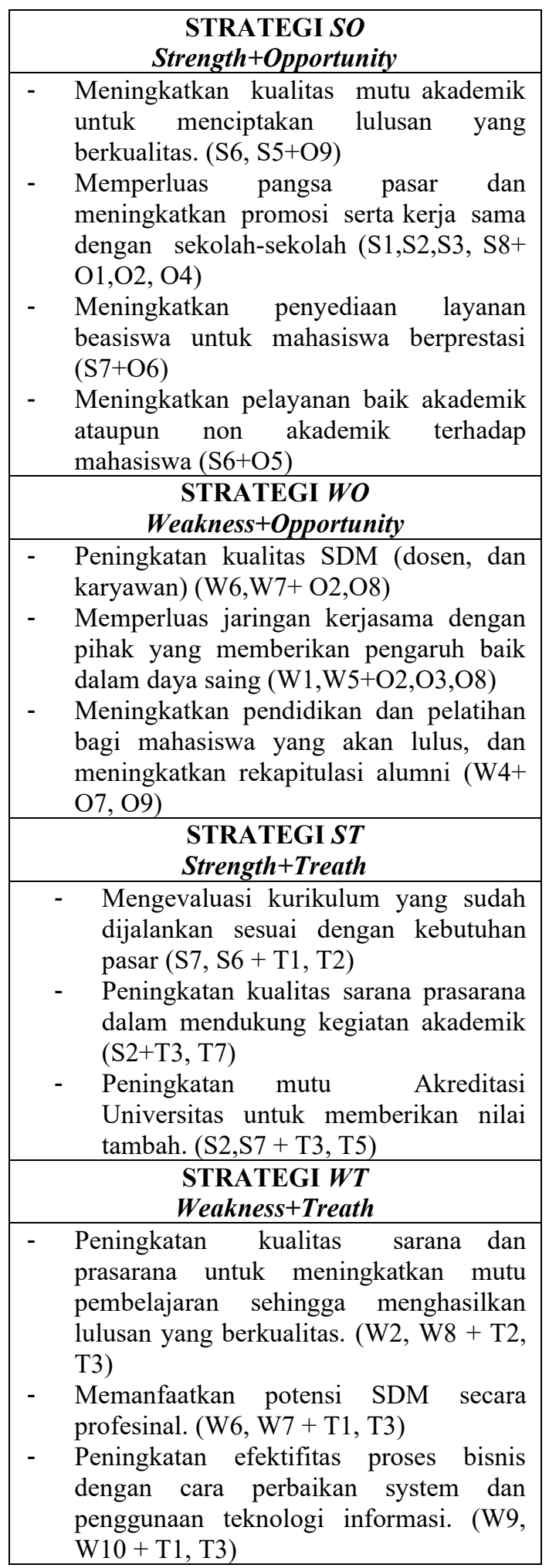

\section{B. Analisis Value Chain}

Analisis value chain digunakan untuk memetakan aktivitas yang ada di Universitas Sangga Buana YPKP Bandung. Dimana terdapat dua aktivitas yang penting dalam analisis Value Chain berdasarkan wawancara, studi dokumen yaitu:

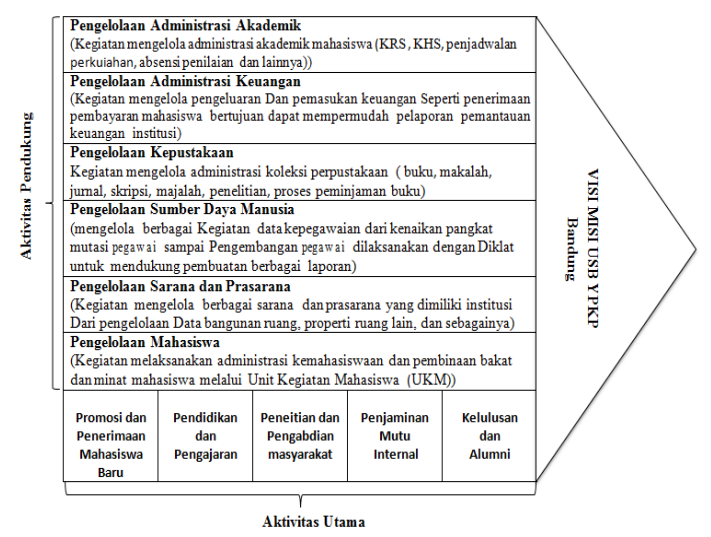

Gambar 4.1 Analisis Value Chain

\subsubsection{Analisis Lingkungan Bisnis Eksternal}

Analisis lingkungan bisnis eksternal menggunakan dua tools analisis yaitu: PEST dan Porter's Five Force.

\section{A. Analisis PEST}

Analisis PEST (Politik, Ekonomi, Sosial, Teknologi) ini digunakan untuk menganalisis lingkungan bisnis secara eksternal yang dapat mempengaruhi proses bisnis lembaga atau perusahaan.

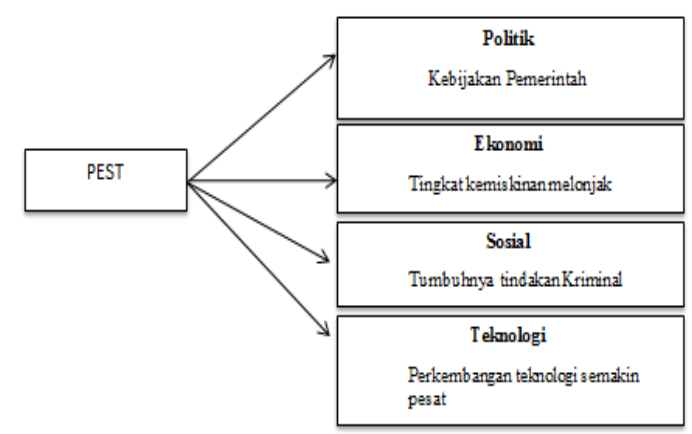

Gambar 4.2 Analisis PEST

\section{B. Analisis Porter's Five Force}

Analisis Porter's Five Force digunakan untuk mengidentifikasi dan menganalisis posisi Universitas Sangga Buana YPKP Bandung dalam instansi Pendidikan yang dapat mempengaruhi proses jalannya bisnis. 


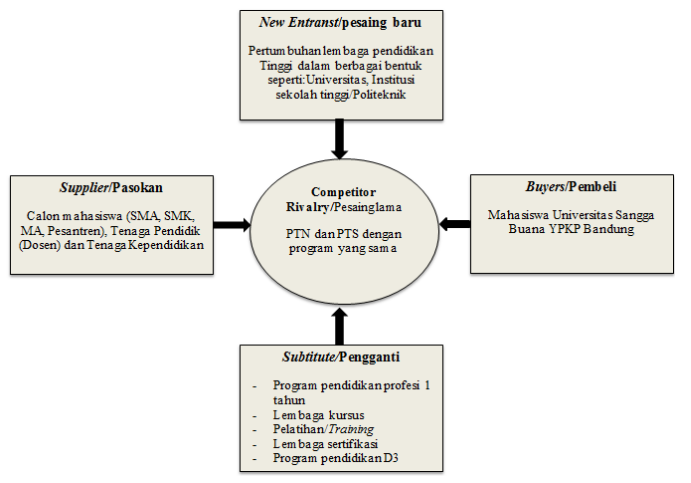

Gambar 4.3 Analisis Porter's Five Force

\subsubsection{Analisis Lingkungan SI/TI Internal}

Analisis lingkungan SI/TI internal dilakukan dengan wawancara dan observasi dengan tujuan menghasilkan gambaran mengenai kondisi sumber daya, infrastruktur, serta portofolio aplikasi saat ini dan dipetakan ke dalam Mc Farlan's Strategic Grid SI/TI yang ada pada Universitas Sangga Buana YPKP Bandung. Dimana sekarang ini Universitas Sangga Buana memiliki unit pengelolaan sistem informasi yaitu Direkotrat Sistem Informasi, Mutimedia, dan Pangkalan Data (Dir.SIM \& PD).

Aplikasi yang ada kemudian dipetakan ke dalam Mc Farlan's Strategic Grid yang terdiri dari strategic, high potential, key operational dan support. Dalam pemetaan dibuat pertanyaan (kuesioner) untuk mengetahui penempatan dari tiap-tiap aplikasi yang ada. Selanjutnya pertanyaan kuesioner dapat dilihat lengkap pada lampiran tentang pertanyaan aplikasi sistem informasi menurut Ward and Peppard.

Berdasarkan hasil kuesioner maka dapat dipetakan beberapa aplikasi saat ini seperti pada tabel 4.6

Tabel 4.6 Portofolio Aplikasi Saat Ini

\begin{tabular}{|c|c|}
\hline Strategic & High Potensial \\
\hline PMB & \\
Tracer Study & \\
Asset Management & \\
Website & \\
\hline & \\
\hline SI Akademik & Billing \\
E-Learning & Repository \\
Keuangan & Research \\
Penjaminan Mutu & Jurnal \\
Perpustakaan & SI Absensi \\
Kepegawaian & \\
\hline Key Operational & Support \\
\hline
\end{tabular}

\subsubsection{Analisis Lingkungan SI/TI Eksternal}

Perkembangan teknologi informasi Setiap tahun berkembang sangat pesat. Dimana penyebabnya dikarenakan kebutuhan organisasi bergantung kepada teknologi informasi dalam proses bisnisnya semakin banyak.

Berdasarkan hasil studi literatur dan wawancara, ada beberapa tren teknologi informasi dapat dimanfaatkan oleh Universitas Sangga Buana YPKP Bandung antara lain Teknologi cashless Big Data, Teknologi Web, Google Cloud Platfrom (GCP), Aplikasi Mobile dan Teknologi Smart Card.

\subsection{Hasil}

Langkah selanjutnya yang dilakukan setelah menganalisis kebutuhan bisnis baik internal dan eksternal, lingkungan SI/TI baik internal dan eksternal adalah memformulasikan perencanaan strategis SI/TI Universitas Sangga Buana YPKP Bandung.

Dimana Strategi SI ini menentukan portofolio aplikasi SI Universitas Sangga Buana YPKP Bandung yang harus dibangun. Sedangkan Strategi TI digunakan untuk menentukan infrastruktur TI yang diperlukan dalam mendukung strategi SI. Sedangkan strategi manajemen SI/TI menentukan aturan dalam mendukung rekomendasi strategi bisnis SI dan strategi TI.

Berikut ini adalah rekomendasi formulasi perencanaan strategis SI/TI Universitas Sangga Buana YPKP Bandung.

\subsubsection{Strategi Bisnis SI}

Setelah melalui analisis SWOT, Value Chain, PEST dan Porter's Five Force yang telah dilakukan sebelumnya, maka didapatkan rekomendasi kebutuhan terhadap sistem informasi yang dapat diimplementasikan di Universitas Sangga Buana YPKP Bandung.

Dimana tujuan rekomendasi strategi bisnis SI adalah untuk memberikan usulan aplikasi sistem informasi di masa yang akan mendatang yang sesuai dengan strategi bisnis perusahaan

Berdasarkan hasil analisis diatas maka ada 24 aplikasi sistem informasi yang dibutuhkan di Universitas Sangga Buana YPKP Bandung berdasarkan analisis dan tools yang digunakan. Maka dari Tabel 4.7 dapat 
ditarik kesimpulan bahwa ada 10 diantaranya sudah dimiliki namun masih membutuhkan penyempurnaan (Upgrade) agar dapat digunakan secara maksimal untuk memenuhi kebutuhan bisnis perguruan tinggi, Lima(5) diantaranya telah dimiliki dan bisa dilanjutkan (Continue) karena masih dianggap cocok dengan strategi ke depan serta Sembilan lainnya memerlukan aplikasi baru (New System) agar pekerjaan menjadi lebih efektif dan efisien di Universitas Sangga Buana YPKP Bandung.

Tabel 4.7 Rekomendasi Aplikasi

\begin{tabular}{|c|c|c|c|}
\hline No & Nama Aplikasi & Status & $\begin{array}{c}\text { Rekomen } \\
\text { dasi }\end{array}$ \\
\hline 1 & Website usbypkp & Ada & Upgrade \\
\hline 2 & $\begin{array}{l}\text { SI Pendaftaran } \\
\text { mahasiswa Baru }\end{array}$ & Ada & Continue \\
\hline 3 & $\begin{array}{l}\text { SI penjaminan } \\
\text { mutu }\end{array}$ & Ada & Upgrade \\
\hline 4 & SI kepegawaian & Ada & Upgrade \\
\hline 6 & SI Carrer Center & $\begin{array}{l}\text { Tidak } \\
\text { Ada }\end{array}$ & New \\
\hline 5 & SI kerjasama & $\begin{array}{l}\text { Tidak } \\
\text { Ada }\end{array}$ & New \\
\hline 7 & $\begin{array}{c}\text { SI Asset } \\
\text { management }\end{array}$ & Ada & Continue \\
\hline 8 & E-Learning & Ada & Upgrade \\
\hline 9 & $\begin{array}{l}\text { SI penelitian dan } \\
\text { pengabdian } \\
\text { masyarakat }\end{array}$ & $\begin{array}{c}\text { Tidak } \\
\text { Ada }\end{array}$ & $\mathrm{New}$ \\
\hline 10 & SI wisuda Online & $\begin{array}{c}\text { Tidak } \\
\text { Ada }\end{array}$ & new \\
\hline 11 & $\begin{array}{l}\text { SI Alumni dan } \\
\text { Tracer Study }\end{array}$ & ada & Upgrade \\
\hline 12 & SI Akademik & Ada & Upgrade \\
\hline 13 & SI Absensi & Ada & Upgrade \\
\hline 14 & SI perwalian & $\begin{array}{c}\text { Tidak } \\
\text { ada }\end{array}$ & New \\
\hline 15 & SI Keuangan & Ada & Upgrade \\
\hline 16 & Billing & Ada & Continue \\
\hline 17 & SI Perpustakaan & Ada & Upgrade \\
\hline 18 & SI Repository & Ada & Continue \\
\hline 19 & SI Jurnal & Ada & Upgrade \\
\hline 20 & SI Research & Ada & Continue \\
\hline 21 & SI kemahasiswaan & $\begin{array}{c}\text { Tidak } \\
\text { Ada }\end{array}$ & $\mathrm{New}$ \\
\hline 22 & SI Beasiswa & $\begin{array}{c}\text { Tidak } \\
\text { Ada }\end{array}$ & New \\
\hline 23 & SI Terintegrasi & $\begin{array}{c}\text { Tidak } \\
\text { Ada }\end{array}$ & $\mathrm{New}$ \\
\hline 24 & Data Warehouse & $\begin{array}{c}\text { Tidak } \\
\text { Ada }\end{array}$ & $\mathrm{New}$ \\
\hline
\end{tabular}

\subsubsection{Strategi TI}

Universitas Sangga Buana YPKP Bandung dapat memanfaatkan teknologi informasi dalam mencapai tujuan bisnisnya, dimana tujuan rekomendasi strategi TI adalah untuk mendukung kebutuhan dari strategi bisnis SI. Strategi TI itu sendiri sebagai berikut:

1. Mengaudit/menilai ulang SI/TI yang ada di Universitas Sangga Buana YPKP Bandung.

Dimana dari menilai ulang SI/TI saat ini diakukan untuk meninjau kembali fungsi teknologi Universitas Sangga Buana YPKP Bandung secara berkala sehingga benar-benar tepat.

2. Melakukan Standarisasi SI/TI

Melakukan standarisasi SI/TI baik dari sisi perangkat keras (hardware) maupun perangkat lunak (software) dari aplikasi sistem informasi untuk memudahkan maintenance. Selain itu, perlu dilakukan legalisasi seluruh software dan aplikasi yang dipakai di lingkungan Universitas Sangga Buana YPKP Bandung.

3. Membuat teknologi mudah digunakan Strategi bisnis TI yang mengacu kepada kemudahan penggunaan teknologi bagi user sehingga tidak merasa kesulitan, seperti dalam pembuatan antar muka(interface) sederhana dan mudah dipahami dan digunakan.

4. Melakukan Pemancaran atau penyebaran Access Point (AP)

Tujuan dari Pemancaran atau penyebaran access point agar jaringan internet bisa digunakan secara maksimal oleh pengguna untuk melancarkan aktivitas tanpa adanya hambatan jaringan internet. Sekarang ini semakin bertambahnya pengguna jaringan internet dalam suatu gedung maka access point yang dibutuhkan semakin banyak. Perlunya melakukan penyebaran, penempatan AP dengan tepat di setiap ruangan. kinerja jaringan internet akan lebih optimal apabila penempatan AP dalam suatu gedung dapat dilakukan dengan tepat.

\subsubsection{Strategi Manajemen SI/TI}

Rekomendasi strategi manajemen SI/TI bertujuan untuk memberikan usulan yang berupa kebijakan-kebijakan dalam menerapkan strategi SI/TI, sehingga nantinya 
dapat dijadikan strategi oleh Universitas Sangga Buana YPKP Bandung antara lain sebagai berikut:

1. Melakukan strategi pengembangan sistem informasi pada beberapa bidang: seperti infrastruktur TI, sistem aplikasi, dan layanan SI/TI.

2. Kebijakan standarisasi SI/TI baik dari sistem perangkat keras (hardware) maupun perangkat lunak (software).

3. Kebijakan standarisasi sistem manajemen

\subsection{Portofolio Aplikasi SI mendatang dengan tools MC Farlan's Strategic Grid}

Tabel 4.8 Portofolio SI Mendatang

\begin{tabular}{|l|l|}
\hline \multicolumn{1}{|c|}{ Strategic } & \multicolumn{1}{c|}{ High Potensial } \\
\hline$\sim$ PMB & +SI kerjasama \\
$*$ Tracer Study & +SI Carrer Center \\
$\sim$ & +SI wisuda \\
Management & +SI Penelitian dan \\
$*$ Website & Pengabdian pada \\
& Masyarakat \\
& +SI perwalian \\
& +SI kemahasiswaan \\
& +SI Beasiswa \\
& +SI Terintegrasi \\
& +Data warehouse \\
\hline * SI Akademik & $\sim$ Billing \\
*E-Learning & $\sim$ Repository \\
* Keuangan & $\sim$ Research \\
*Penjaminan & *Jurnal \\
Mutu & * SI Absensi \\
* Perpustakaan & \\
* Kepegawaian & \\
\hline Key Operational & \multicolumn{1}{c|}{ Support } \\
\hline
\end{tabular}

Ket : *Upgrade, $\sim$ Continue, + New

Semua sistem informasi yang belum ada di universitas Sangga Buana YPKP Bandung di posisikan ke dalam high Potensial karena sistem belum diketahui manfaatnya akan efektif secara langsung yang dirasakan oleh setiap unit.

\section{KESIMPULAN DAN SARAN}

\subsection{Kesimpulan}

Berdasarkan analisis dan pembahasan yang telah diuraikan di bab sebelumnya, maka diperoleh kesimpulan penelitian ini adalah sebagai berikut:
1. Perencanaan strategis sistem informasi menggunakan metode Ward and Peppard menghasilkan kerangka kerja strategis, digunakan untuk menyelaraskan antara kebutuhan strategi bisnis dan strategi SI/TI untuk mendapatkan keunggulan kompetitif sesuai dengan tujuan Universitas Sangga Buana YPKP Bandung.

2. Dengan menggunakan perencanaan strategis sistem informasi, universitas dapat mengetahui faktor-faktor penting yang berpengaruh dalam mengembangkan suatu sistem informasi

3. Perencanaan strategis sistem informasi menghasilkan analisis bisnis, analisis SI/TI baik Internal dan Eksternal yang telah diterapkan menggunakan tools SWOT, Value Chain, PEST dan Porter five's Force

4. Perencanaan strategis sistem informasi menghasilkan solusi strategi Bisnis, Strategi SI/TI, dan strategi managemen SI/TI.

5. Memetakan sistem informasi yang sudah ada dan aplikasi yang direkomendasikan berdasarkan analisis dan pembahasan dimana rekomendasi 24 aplikasi , 10 sistem yang perlu di upgrade, 5 sistem yang dilanjutkan dan 9 sistem yang baru

5.2 Saran

Adapun saran yang yang diuraikan yaitu:

1. Universitas Sangga Buana YPKP Bandung bisa terus melakukan pengembangkan dan meningkatkan perencanaan strategis sistem informasi sesuai dengan perkembangan yang ada.

2. Dalam menyusun perencanaan strategis selanjutnya bisa menambahkan atau mengkombinasikan metode lain dalam penelitiannya seperti metode yang lainnya.

3. Dalam menyusun perencanaan strategis bisa dikembangkan dalam penggunaan tools yang lain

4. Proses penelitian dalam perencanaan strategis SI/TI bisa direncanakan secara luas atau seluruh aspek misalnya menambahkan perencanaan anggaran, sumber daya yang ada dan jaringan.

\section{DAFTAR PUSTAKA}

[1] Ward. John. And Joe Peppard., Strategic Planning For Information Sistem 3th ed. 
England: John Wiley \& Sons, 2002. 2002.

[2] W. Titthasiri, "Information Technology Strategic Planning Process for Institutions of Higher Education in Thailand," NECTEC Tech. J., 2001.

[3] K. C. Laudon and J. P. Laudon, Managing Information Systems: Managing the Digital Firm 13ed. 2014.

[4] J. HartonoMusakini, "Analisis \& Desain Sistem Informasi Sitem Informasi: Pendekatan terstruktur teori dan praktik aplikasi bisnis," in Analisis \& Desain Sistem Informasi Sitem Informasi: Pendekatan terstruktur teori dan praktik aplikasi bisnis, 2014.

[5] J. Ward and J. Peppard, Success Factors in Strategic Information Systems. 2002.
[6] M. Afriyano, E. Darwiyanto, and G. A. A. Wisudiawan, "Perencanaan Strategis Sistem Informasi Menggunakan Metode Ward and Peppard Pada PT. Grahacipta Bangko Jaya," e-Proceeding Eng., 2016.

[7] P. Widyaningsih, M. Mustafid, and A. F. Rochim, "Perencanaan Strategis Sistem Informasi Pada Institusi Pendidikan Tinggi Menggunakan Analisis Critical Success Factors," J. Sist. Inf. BISNIS, 2014, doi: 10.21456/volliss2pp86-92.

[8] G. A. F. Maulani and N. A. Hamdani, "Perencanaan Strategis Sistem Informasi pada Perguruan Tinggi Swasta di Indonesia," J. Petik, vol. 4, no. 2, pp. 162-166, 2018, doi: 10.31980/jpetik.v4i2.367. 